\title{
A Mathematical Function for Crop Growth Based on Light Interception and Leaf Area Expansion
}

\author{
J. GOUDRIAAN* and J. L. MONTEITH $\dagger$
}

* Department of Theoretical Production Ecology, Agricultural University, PO Box 430, 6700AK Wageningen, The Netherlands and $†$ International Crops Research Institute for the Semi-Arid Tropics, Patancheru, A.P. 502324, India

Accepted: 27 June 1990

\section{ABSTRACT}

The Richards function is often inappropriate to describe growth for crop stands, in which dry matter characteristically increases at an almost constant rate during the main growth stage. An alternative function with a more physiological basis is developed by assuming that, when light is limiting, growth rate is proportional to intercepted radiation and therefore to an exponential function of leaf area. As the function describes the transition from exponential to linear growth, the name expolinear growth equation is proposed. The parameters of the equation are an initial maximum relative growth rate $R_{\mathrm{m}}$, a maximum absolute growth rate $C_{\mathrm{m}}$, and a time $t_{\mathrm{b}}$ at which the stand effectively passes from exponential to linear growth. The ratio $R_{\mathrm{m}} / C_{\mathrm{m}}$ is the product of a light attenuation coefficient $K$, a specific leaf area $s$, and a ratio of leaf weight to total plant weight $p_{1}$. The time $t_{\mathrm{b}}$ 'lost' for growth while the canopy is closing is proportional to the logarithm of fractional light interception at emergence and inversely proportional to $R_{\mathrm{m}}$. Termination of growth is accounted for by truncation of the expolinear equation.

Applications of this type of analysis are given for sorghum and faba bean. The descriptive power of the equation is illustrated for oil palm. Implications for optimum growth strategies are reviewed and caveats are entered.

Key words: Crop growth, mathematical function, light interception, leaf area expansion, models of growth, expolinear equation.

\section{INTRODUCTION}

The concepts of relative growth rate $(R)$, introduced by Blackman (1919), and of net assimilation rate $(E)$ by Gregory (1918) provided the beginnings of a rational basis for analysing the growth of single plants. Under constant environmental conditions both quantities were found to be stable during the early life of a seedling but then decreased with time, first because of mutual shading by leaves and later because of senescence.

In plant communities and particularly in closelyspaced stands of agricultural crops, competition for light begins within a few weeks of emergence and is the major reason for the rapid decline of both $R$ and $E$. In consequence, attempts to correlate these quantities with changes in the environment during the growing season have rarely been successful, and the so-called 'classical approach' to growth analysis is little used by contemporary agronomists.

Another school of plant analysts has attempted

* For correspondence.

0305-7364/90/120695+07\$03.00/0 to find mathematical functions that describe how biomass changes with time (Richards, 1969; Causton and Venus, 1981). Most of these functions are asymptotic and include final size as an essential parameter. The Richards function has been successfully applied to describe the growth of organs, but is rarely appropriate for field crops. The growth rate of a healthy crop is usually stable for a major part of the growing season, e.g. as demonstrated by Sibma (1968) for arable crops grown in the Netherlands. For such a situation, the Richards function fails to follow the relatively strong curvature during the early exponential phase of growth and again during senescence.

We have developed a process-based equation for crop growth, exploiting evidence from agriculture and forestry that uniform stands of vegetation accumulate dry matter at a rate closely related to the rate at which foliage intercepts (or absorbs) radiant energy (Russell, Jarvis and Monteith, 1989). Our equation allows d. wt, leaf area, relative growth rate and net assimilation rate to be expressed as consistent functions of time, avoiding arbitrary constants by using measurable para-

(C) 1990 Annals of Botany Company 
meters wheh havestmple physteator phystologiea significance. The exercise can therefore be regarded as a step towards developing a 'mechanistic' type of growth analysis which may help to reconcile the distinction between classical and functional analyses which has exercised Hunt (1982) and others.

\section{DERIVATION}

\section{Leaf growth}

Evidence for many types of vegetation, growing in a uniform stand, suggests that for most practical purposes the fraction $f$ of incident radiation intercepted by foliage can be adequately described by Beer's function

$$
f=1-\exp (-K L) .
$$

Here, $L$ is the leaf area index and $K$ is the light extinction coefficient which depends on the average spectral properties of leaves and on their orientation in relation to the spatial distribution of solar radiation. In theory, stands with randomly spaced opaque, horizontal leaves have $K=1$. In practice, $K$ ranges from about 0.9 for planophile canopies to $0 \cdot 3$ for erectophile canopies with clustered leaves. In the limit when $K L$ is small, as at emergence in most crop stands,

$$
f \sim K L .
$$

The relation between dry matter production and light absorption, already referred to, has usually been validated by measuring the weight of shoots only but there is no reason to suppose that it should not hold for total d. wt $W$, increasing at a time-dependent rate $C$. We therefore write

$$
\frac{\mathrm{d} W}{\mathrm{~d} t}=C=f C_{\mathrm{m}}=[1-\exp (-K L)] C_{\mathrm{m}},
$$

where $C_{\mathrm{m}}$ is a maximum value of $C$ that would be achieved if all incident light were intercepted ( $f=$ 1). In practice, $f$ rarely exceeds 0.95 , apparently because of the death of heavily shaded leaves at the bottom of the canopy (Monteith and Elston, 1983).

Suppose that the fraction of growth of total dry matter allocated to new leaves (dynamic leaf weight ratio) is $p_{1}$ and that the specific leaf area of these leaves is $s\left(\mathrm{~m}^{2}\right.$ per $\mathrm{g}$ leaf). Then, from eqn (2),

$$
\mathrm{d} L / \mathrm{d} t=f C_{\mathrm{m}} p_{1} s
$$

and from eqn (1),

$$
\frac{\mathrm{d} L}{1-\exp (-K L)}=p_{1} s C_{\mathrm{m}} \mathrm{d} t
$$

A general analytical solution of eqn (4) can be

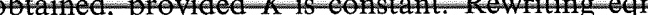
(4), its integration proceeds along the following lines

$$
\frac{\exp (K L) \mathrm{d} L}{\exp (K L)-1}=p_{1} s C_{\mathrm{m}} \mathrm{d} t,
$$

which can be integrated to

$$
\ln \left(\frac{\exp (K L)-1}{\exp \left(K L_{0}\right)-1}=p_{1} s C_{\mathrm{m}} t\right.
$$

An explicit expression for $L$ is

$L=\frac{1}{K} \ln \left\{1+\left[\exp \left(K L_{0}\right)-1\right] \exp \left(\int_{0}^{t} K p_{1} s C_{\mathrm{m}} \mathrm{d} t\right)\right\}$,

where $L_{0}$ is the initial leaf area index, equal to the leaf area per plant $\left(A_{0}\right)$ times the population density $N\left(\mathrm{~m}^{-2}\right)$. The multiplication factor $\left[\exp \left(K L_{0}\right)-1\right]$ can also be written as $f_{0} /\left(1-f_{0}\right)$, where $f_{0}$ is the fractional light interception at time zero [eqn (1)]. When $f_{0}$ is very small, as it usually is, the division by $\left(1-f_{0}\right)$ can be omitted. Equation (7) ceases to be valid when the oldest leaves begin to die.

As long as $K L$ is still small, eqn (4) reduces to

$$
\frac{\mathrm{d} L}{L}=K p_{1} s C_{\mathrm{m}} \mathrm{d} t
$$

which can be integrated to

$$
L=L_{0} \exp \left(\int_{0}^{t} K p_{1} s C_{\mathrm{m}} \mathrm{d} t\right)
$$

When $K p_{1} s C_{\mathrm{m}}$ is constant, the time-integral of $K p_{1} s C_{\mathrm{m}}$ in eqns (7) and (9) can be replaced by $R_{\mathrm{m}} t$, where $R_{\mathrm{m}}$ is the maximum relative growth rate given by

$$
R_{\mathrm{m}}=K p_{1} s C_{\mathrm{m}} .
$$

Independently, Ferrandino (1989) derived an expression for leaf area growth with the same form as eqn (7), and used it to investigate the defoliation of diseased potato plants.

\section{Biomass growth}

Biomass growth can now be expressed as a function of time, using eqn (2) for the relation between growth and intercepted radiation and eqn (7) for leaf area index, to give:

$$
\frac{\mathrm{d} W}{\mathrm{~d} t}=C_{\mathrm{m}} \frac{\left[\exp \left(K L_{0}\right)-1\right] \exp \left(\int_{0}^{t} K p_{1} s C_{\mathrm{m}} \mathrm{d} t\right)}{1+\left[\exp \left(K L_{0}\right)-1\right] \exp \left(\int_{0}^{t} K p_{1} s C_{\mathrm{m}} \mathrm{d} t\right)} .
$$


This fanty complex equation can be simplified considerably when $C_{\mathrm{m}}$ and $p_{1} s$ are constant $(K$ was assumed constant at an earlier stage of the derivation). Then, the ratio of the increments of leaf area and total biomass remain constant during the growth of the crop.

The Leaf Area Ratio (LAR) from classical growth analysis is commonly used for the ratio of accumulated leaf area to standing above-ground biomass. To make the transition from leaf area growth to biomass growth, we use the ratio $p_{1} s$, which stands for the ratio of increments of leaf area and biomass. We assume that this ratio is constant, so that total and incremental values are the same. Moreover, the relative growth rate for biomass is then the same as for leaf area. We are aware that in many situations this assumption is not correct, but the equations can be extended by one parameter in such cases, if required.

Equation (11) can now be written as

$$
C=\frac{\mathrm{d} W}{\mathrm{~d} t}=C_{\mathrm{m}} \frac{\left[\exp \left(K L_{0}\right)-1\right] \exp \left(R_{\mathrm{m}} t\right)}{1+\left[\exp \left(K L_{0}\right)-1\right] \exp \left(R_{\mathrm{m}} t\right)} \text {. }
$$

The ratio $C / C_{\mathrm{m}}$ was earlier identified as the fractional light interception $f$. Equation (12) shows that this ratio follows a simple logistic growth curve to an asymptotic level of unity.

Integration of eqn (12), along similar lines as with eqn (9), gives

$$
W=\left(C_{\mathrm{m}} / R_{\mathrm{m}}\right) \ln \left[1+\frac{f_{0}}{1-f_{0}} \exp \left(R_{\mathrm{m}} t\right)\right] .
$$

When $t$ is large, the increase of biomass with time approaches a constant rate $C_{\mathrm{m}}$. Neglecting the term $1, W$ can be written as

$$
W=\left(C_{\mathrm{m}} / R_{\mathrm{m}}\right) \ln \left(\frac{f_{0}}{1-f_{0}}\right)+C_{\mathrm{m}} t
$$

This equation remains valid even after the oldest leaves begin to die, provided ground cover remains complete and dead biomass is included in $W$. When $W$ is extrapolated (Fig. 1), the intercept with the time axis is given by

$$
t_{\mathrm{b}}=-\ln \left\{\frac{f_{0}}{1-f_{0}}\right\} / R_{\mathrm{m}} .
$$

Substituting $f_{0} /\left(1-f_{0}\right)$ from this equation into eqn (13) gives

$$
W=\left(C_{\mathrm{m}} / R_{\mathrm{m}}\right) \ln \left\{1+\exp \left[R_{\mathrm{m}}\left(t-t_{\mathrm{b}}\right)\right]\right\},
$$

which we shall refer to as the expolinear growth equation. In this equation, the $d$. wt of a stand can

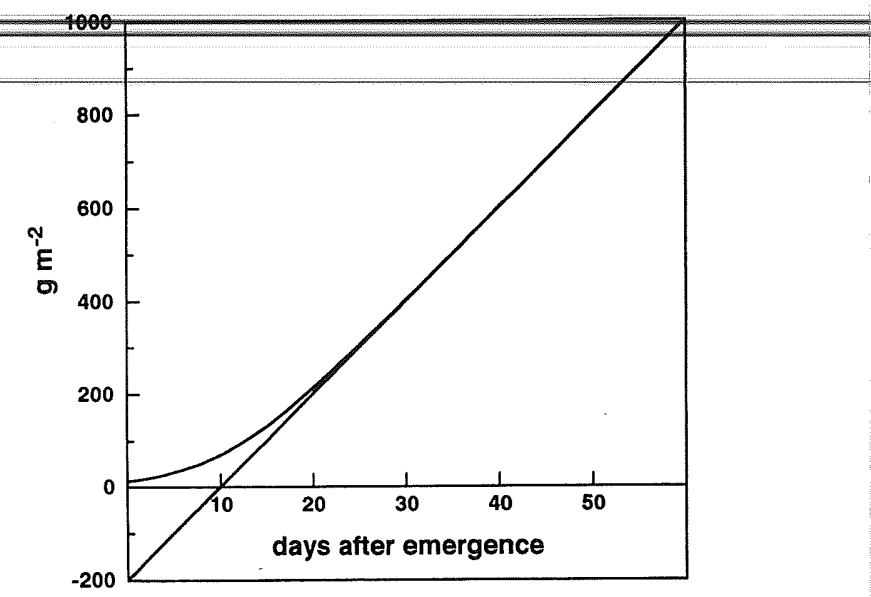

Fig. 1. The expolinear growth equation, and its linear asymptote. In this example the value of $t_{\mathrm{b}}$ is $10 \mathrm{~d}$.

be specified as a function of its maximum growth rate $C_{\mathrm{m}}$ and its maximum relative growth rate $R_{\mathrm{m}}$. The time parameter $t_{\mathrm{b}}$, which determines the position of the curve on the time-axis, has been referred to as 'lost time' (Monteith, 1981; Monteith and Scott, 1982). The corresponding effective loss of biomass $\left(C_{\mathrm{m}} t_{\mathrm{b}}\right)$ can be written as $-\ln \left[f_{0} /\left(1-f_{0}\right)\right] /\left(K p_{1} s\right)$, so this loss is independent of $C_{\mathrm{m}}$.

\section{Termination of growth}

Equation (16) implies that the growth of a crop stand can be divided into two phases. In the first exponential phase, growth rate increases from a very small value on the day of emergence to a maximum rate $C_{\mathrm{m}}$, achieved soon after $t_{\mathrm{b}}$. In the second linear phase, this constant maximum growth rate is maintained providing the environment remains constant. Description of the third phase in which $C$ decreases as a consequence of senescence requires an extension of eqn (16). No matter what form this description takes, at least one more parameter is required, e.g. the asymptotic maximum $W_{\mathrm{m}}$, or the time when growth stops $t_{\mathrm{r}}$.

We decided to use a simple truncation of the expolinear equation when $W$ reaches the maximum level $W_{\mathrm{m}}$, i.e.

$W=\min \left\langle W_{\mathrm{m}},\left(C_{\mathrm{m}} / R_{\mathrm{m}}\right) \ln \left\{1+\exp \left[R_{\mathrm{m}}\left(t-t_{\mathrm{b}}\right)\right]\right\}\right\rangle$.

The maximum d. wt $W_{\mathrm{m}}$ is related to the time when growth stops by

$$
W_{\mathrm{m}}=C_{\mathrm{m}}\left(t_{\mathrm{p}}-t_{\mathrm{b}}\right) \text {. }
$$




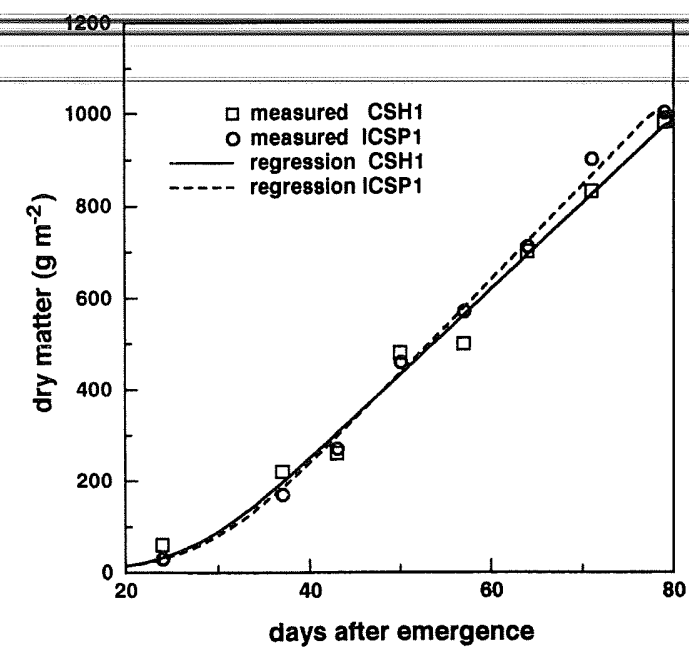

FIG. 2. Shoot d. wt of sorghum as a function of days from emergence from measurements at ICRISAT (see text). Fitted curves derived from eqn (13).

\section{ILLUSTRATIONS}

\section{Sorghum}

In Fig. 2, measured above-ground d. wts of two cultivars of sorghum (CSH1 and ICSP1) are given as a function of time. The two stands grew on a vertisol at International Crops Research Institute for the Semi-Arid Tropics during the rainy season of 1981. The stands were well fertilized and the distribution of rain was such that growth was never restricted by a shortage of water in the root zone which extended to about $1.5 \mathrm{~m}$.

The attenuation coefficient for light was estimated by assuming that $95 \%$ of incidence radiation was intercepted when the leaf area index

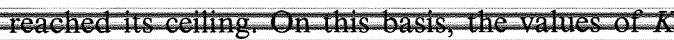
from eqn (1) were 0.65 for CSH1 and 0.53 for ICSP1, respectively. Values of $C_{\mathrm{m}}$ and $t_{\mathrm{b}}$ were obtained from a linear regression of $d$. wt on time over the period when $C_{\mathrm{m}}$ appeared to be constant, i.e. from about $30 \mathrm{~d}$ to $79 \mathrm{~d}$ when the regression was truncated (Table 1). The value of $R_{\mathrm{m}}$ could then be calculated using eqn (10). Using these parameter values, the expolinear function was then plotted in Fig. 2 for both cultivars separately.

\section{Faba bean}

Figure 3 shows the above-ground $d$. wts of a

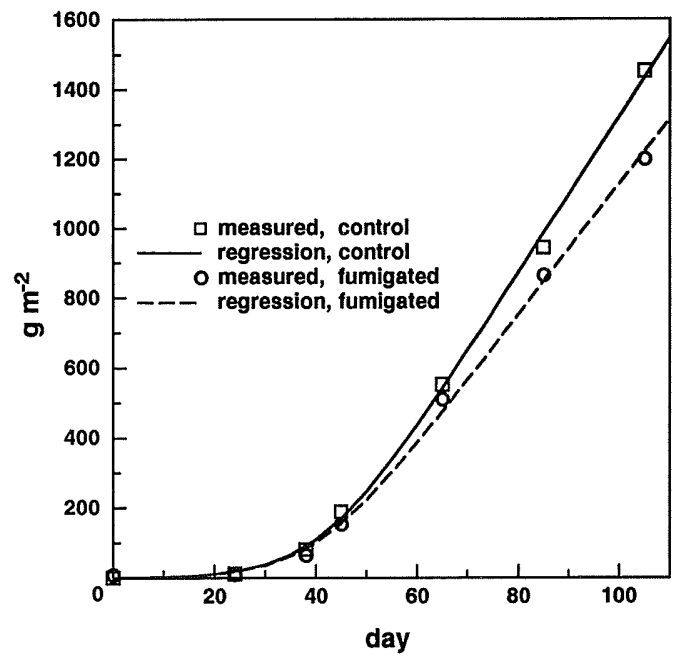

Fig. 3. Shoot dry matter of two crops of Faba bean, with and without fumigation of $\mathrm{SO}_{2}$ (Kropff et al., 1989). The expolinear plot was drawn with the parameter values as in Table 2.

TABLE 1. Parameter values for sorghum cultivars

\begin{tabular}{|c|c|c|}
\hline & $\mathrm{CSH} 1$ & ICSP1 \\
\hline Recorded plant density $N\left(\mathrm{~m}^{-2}\right)$ & $18 \cdot 4$ & 16.9 \\
\hline $\begin{array}{l}\text { Assumed or independently measured } \\
\text { Maximum dry weight } W_{\mathrm{m}}\left(\mathrm{g} \mathrm{m}^{-2}\right) \\
\text { Reached at day } t_{\mathrm{p}}(\mathrm{d}) \\
\text { Extinction coefficient } K(-) \\
\text { 'LAR' } p_{1} s\left(\mathrm{~m}^{2} \mathrm{~g}^{-1}\right)\end{array}$ & $\begin{array}{l}980 \\
79 \\
0 \cdot 65 \\
0 \cdot 02\end{array}$ & $\begin{array}{c}1000 \\
79 \\
0 \cdot 53 \\
0 \cdot 02\end{array}$ \\
\hline $\begin{array}{l}\text { Fitted } \\
\text { Maximum growth rate } C_{\mathrm{m}}\left(\mathrm{g} \mathrm{m}^{-2} \mathrm{~d}^{-1}\right) \\
\text { Lost time } t_{\mathrm{b}}(\mathrm{d})\end{array}$ & $\begin{array}{l}18 \cdot 6 \pm 1 \cdot 1 \\
26 \cdot 8 \pm 4 \cdot 1\end{array}$ & $\begin{array}{l}20 \cdot 4 \pm 0 \cdot 7 \\
28 \cdot 7 \pm 2 \cdot 2\end{array}$ \\
\hline $\begin{array}{l}\text { Calculated } \\
\text { Maximum rel. growth rate } R_{\mathrm{m}}\left(\mathrm{d}^{-1}\right) \\
\text { Initial } f f_{0}(-) \\
\text { Initial leaf area per plant } A_{0}\left(\mathrm{~m}^{2}\right)\end{array}$ & $\begin{array}{l}0.242 \\
1.52 \times 10^{-3} \\
1.3 \times 10^{-4}\end{array}$ & $\begin{array}{l}0.216 \\
2.0 \times 10^{-3} \\
2.2 \times 10^{-4}\end{array}$ \\
\hline
\end{tabular}




\begin{tabular}{lcc}
\hline \\
\multicolumn{1}{l}{ Control } & Fumigated \\
\hline$R_{\mathrm{m}}\left(\mathrm{d}^{-1}\right)$ & $0 \cdot 127 \pm 0 \cdot 006$ & $0 \cdot 128 \pm 0.009$ \\
$C_{\mathrm{m}}\left(\mathrm{g} \mathrm{m}^{-2} \mathrm{~d}^{-1}\right)$ & $22.5 \pm 1 \cdot 1$ & $18 \cdot 8 \pm 1 \cdot 2$ \\
$t_{\mathrm{b}}(\mathrm{d})$ & $41 \cdot 3 \pm 1.9$ & $40 \cdot 1 \pm 2 \cdot 7$ \\
\hline
\end{tabular}

crop of Faba bean grown in an experiment to determine the effect of $\mathrm{SO}_{2}$ fumigation on biomass growth (Kropff et al., 1989a). The experiment was done in 1985 with an average concentration of $165 \mu \mathrm{g} \mathrm{SO}_{2} \mathrm{~m}^{-3}$ in the fumigated treatment, and a background concentration of $16 \mu \mathrm{g} \mathrm{SO}_{2} \mathrm{~m}^{-3}$ in the control treatment. Both crops were optimally supplied with water and nutrients, using drip irrigation. For this data set, the parameter values were found by the non-linear optimization package in GENSTAT 4 (Table 2). This package uses a normal least squares criterion.

\section{Oil palm}

To illustrate the general applicability of the expolinear growth equation as a descriptive tool, the equation was applied to annual growth of oil palm over a period of about 10 years. Both the total d. wt of oil palm and the cumulative $d$. wt of fruit bunches could be described by the expolinear equation (Fig. 4).

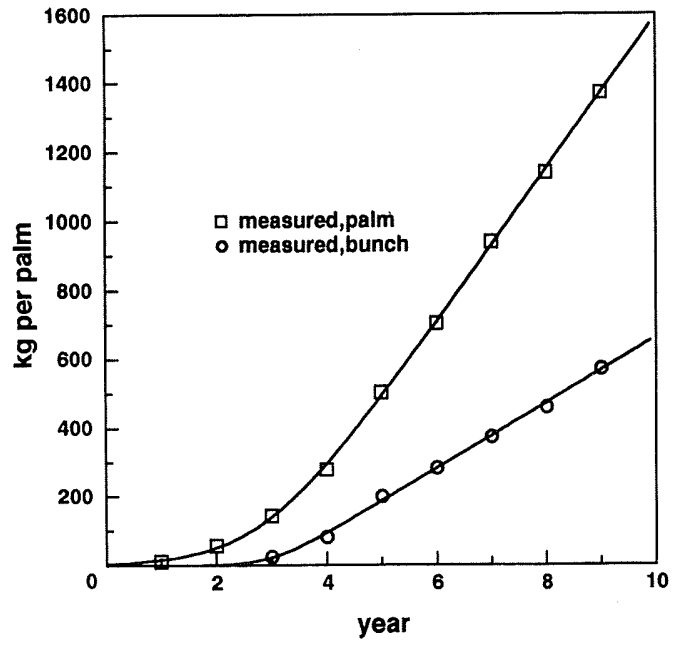

FIG. 4. Annual values of total d. wt and of harvested bunch d. wt per tree of oil palm (cumulative) over a period of several years, and the fit by the expolinear growth equation.
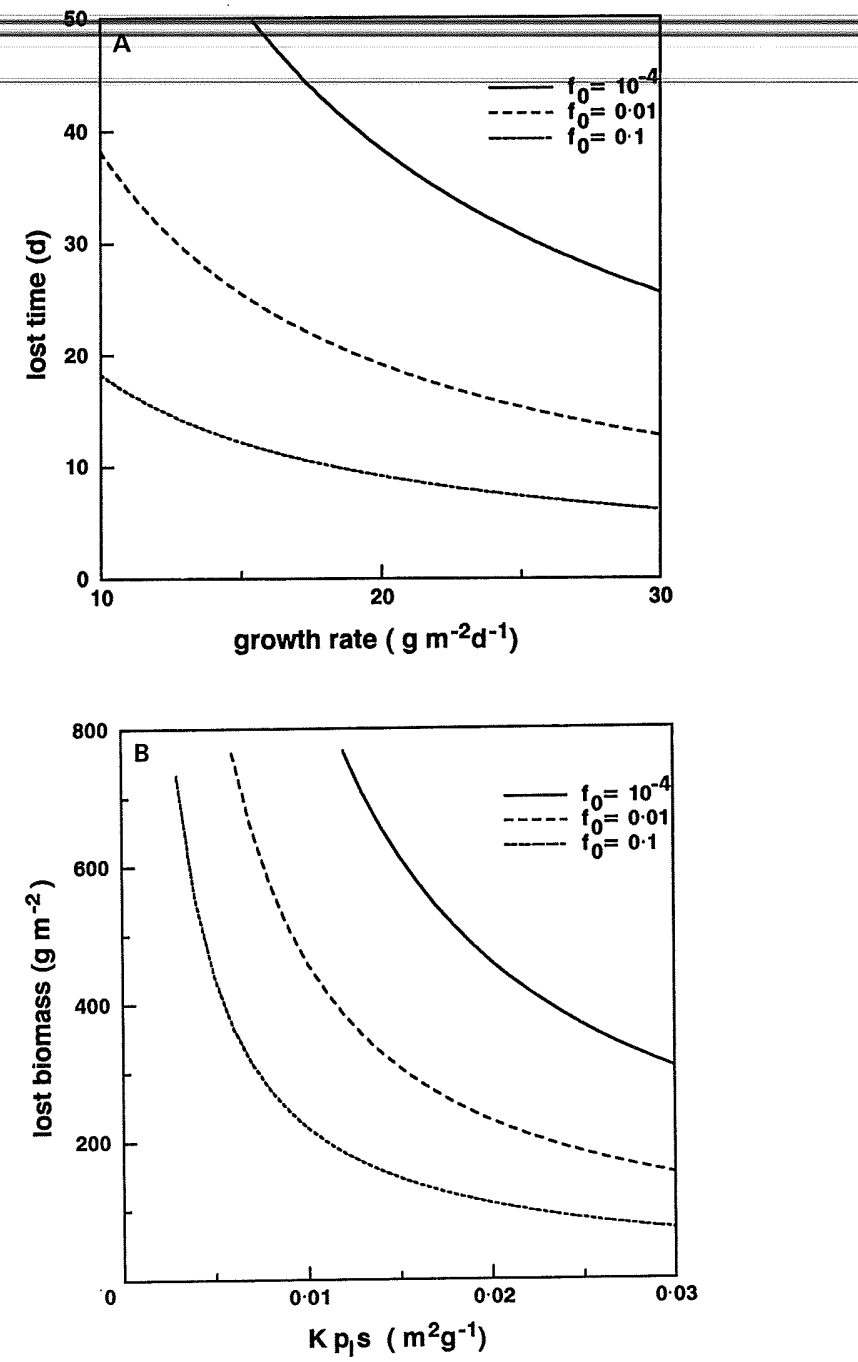

FIG. 5. A, Lost time $t_{\mathrm{b}}$ as function of crop growth rate for three values of initial fractional light interception $f_{0}$ assuming $K p_{1} s=0.012$. B, Lost biomass $C_{\mathrm{m}} t_{\mathrm{b}}$ as function of $K p_{1} s$ for three values of $f_{0}$.

\section{DISCUSSION}

Using typical parameter values for sorghum, $t_{\mathrm{b}}$ was calculated from eqns (10) and (15) as a function of $C_{\mathrm{m}}$, assuming a constant value of $0.012 \mathrm{~m}^{2} \mathrm{~g}^{-1}$ for $K p_{1} s$ (Fig. 5A). Equation (15) implies that $t_{\mathrm{b}}$ is doubled when $R_{\mathrm{m}}$ is halved or when $f_{0}$ is squared. Since the leaf area per plant at emergence is usually independent of plant density, the 'lost time' decreases in proportion to the logarithm of plant density provided there is no self-thinning. The same set of constants was used 
to estimate tost of
$k p$ s. Fig. 5B). The logarithmic relation (with the same restriction) also operates between 'lost biomass' and plant density. For the sorghum trials, the loss of biomass at about $500 \mathrm{~g} \mathrm{~m}^{-2}$ is a substantial fraction of the biomass obtained at harvest-about $1000-1200 \mathrm{~g} \mathrm{~m}^{-2}$. It is therefore worth investigating ways in which this loss might be reduced by increasing one or more of the quantities $K, p_{1}, s, C_{\mathrm{m}}$ and $f_{0}$ as suggested by the relations plotted in Fig. 5. However, examination of these quantities shows that their values are likely to be negatively correlated.

Increasing the specific leaf area $s$ implies thinner leaves, probably transmitting more light and with less photosynthesizing material per unit leaf area. The photosynthesis rate at a given irradiance will then tend to be less (Charles-Edwards, 1982) and so will the value of $K$. It is difficult to predict how a change of specific leaf area would alter the product Ks. Although specific leaf area is often reported from field trials, its relation to productivity has never been clearly established.

Increasing the value of $p_{1}$ implies larger tops but smaller root systems. The benefit of increased light interception may soon be overruled by loss of capacity to absorb water and nutrients. The optimum partitioning pattern is likely to change during plant development. Little is known about the extent to which the partitioning of dry matter can still be improved in actual plant growth.

Larger values of $K$ may stimulate early growth, but will tend to reduce $C_{\mathrm{m}}$ when the plant canopy is closed, because light is less uniformly distributed. There is evidence that the sorghum variety with the larger $K(\mathrm{CSH} 1)$ had a somewhat smaller $C_{\mathrm{m}}$ (see Table 1). This type of difference is expected to be even more prominent in $\mathrm{C}_{3}$ than in $\mathrm{C}_{4}$ species

Because lost biomass is proportional to the logarithm of initial light interception, very large changes of $L_{0}$ or of plant density would be needed to increase production much. Moreover, some self-thinning will occur at later stages of growth, either by death of individuals, but more likely by reduction of individual plant size. Optimum plant densities have been established for many species by agronomic trials, showing that optimum plantdensity for producing biomass is different from the optimum for yield. In grain-bearing species the optimum also depends on the relation between grain number and available assimilate per plant rather than per unit ground area. In short-strawed cereals the optimum densities for biomass and for yield differ less, which may be a secondary reason for their higher yields.

\section{CAVEATS}

Our analysis is valid only when light is the dominant limiting factor (a condition often satisfied in high input agriculture), when there is little change in the receipt of radiation on a weekly, if not on a daily basis (also satisfied except in exceptional weather and when the terms that determine the relative growth rate remain constant (clearly contrary to much experimental evidence). The equation used to relate light interception to leaf area may be a poor approximation during the early stages of a row crop.

The calculated curves shown in Fig. 2 fit the data well; yet a close inspection of the fit at the first harvest (day 24) shows that the calculated biomass of CSH1 at this moment was too low by a factor of 2. It would not have been difficult to remove this discrepancy by applying the full non-linear regression for the whole period at once, but the price to be paid was halving the value of the fitted initial relative growth rate, at variance with the theoretically expected value given in Table 1 . We did not think this was justified on the basis of one measurement. This example emphasizes that to obtain reliable values of initial relative growth rate, many more measurements are needed during early growth than are normally collected.

In the Faba bean example (Fig. 3) the regression showed that the parameter values for both $R_{\mathrm{m}}$ and $t_{\mathrm{b}}$, were almost identical, but that maximum growth rate $C_{\mathrm{m}}$ was reduced by the $\mathrm{SO}_{2}$ fumigation. From eqn (10), the product $K p_{1} s$ must have undergone a compensatory increase. But the measurements did not indicate a change in the extinction coefficient $K$, nor in the leaf partitioning $p_{1}$, and the specific leaf area $s$ decreased (Kropff et al., 1989b). Unfortunately no measurements of shoot-root ratio are available for early growth, but an increase of shoot-root ratio is unlikely. A closer inspection of the data (Kropff et al., 1989 b), shows that a major reason for the smaller $C_{\mathrm{m}}$ of fumigated plants in the linear phase was early leaf abscission, reducing the fractional light interception $f$, to the extent that the potential value of $C_{m}$ was never realized. In this case, the assumptions underlying the derivation of eqns (11) and (16) are invalid, and eqn (10) cannot be applied. However, the expolinear eqn (16) can still be used to establish regressions, provided values of the parameters are carefully interpreted.

We believe the equations will be useful for teaching general principles of crop growth, for helping agronomists, crop physiologists and breeders to interpret their measurements in terms of these principles, and for enabling the wealth of experimental evidence they collect to be sum- 
manzed more streenty, exammed more
insight into governing factors, and extrapolated more confidently to other environments. The expolinear equation has been successfully used to schedule nutrient supply experimentally (Freijsen and Veen, 1989), and it could conceivably be applied to optimize the supply of nutrients in hydroculture or even in field irrigation.

\section{ACKNOWLEDGEMENTS}

We are grateful to Dr A. K. S. Huda for providing measurements of sorghum biomass and leaf area from an unpublished report, and to $\mathrm{Mr}$ W. Gerritsma, Bah Lias Experiment Station, Medan, Indonesia, for providing measurements of oil palm trees.

\section{LITERATURE CITED}

BLACKMAN, V. N., 1919. The compound interest law and plant growth. Annals of Botany 33, 353-60.

Causton, D. R. and Venus, J. C., 1981. The Biometry of Plant Growth, 307 pp. Edward Arnold, London.

Charles-Edwards, D. A., 1982. Physiological Determinants of Growth, 161 pp. Academic Press, Sydney.

FERrandino, F. J., 1989. Spatial and temporal variation of a defoliating plant disease and reduction in yield. Agricultural and Forest Meteorology 47, 273-89.

Freissen, A. H. J. and Veen, B. W., 1989. Phenotypic variation in growth as affected by $\mathrm{N}$-supply: nitrogen productivity, pp. 19-33. In Causes and Consequences of Variation in Growth Rate and Productivity of Higher Plants, ed. H. Lambers, 363 pp. Academic Publishing BV, The Hague, The Netherlands.

Gregory, F. G., 1918. Physiological conditions in cucumber houses. 3rd Annual Report of the Experimental Research Station, Cheshunt, 19-28.

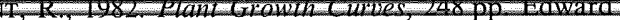
Arnold, London.

KropfF, M. J., MOOI, J., GOUdRIAAN, J., SMEETS, W., LeEmans, A., Kliffen, C. and van Der ZaLm, A. J. A., $1989 a$. The effects of long-term open-air fumigation with $\mathrm{SO}_{2}$ on a field crop of broad bean (Vicia faba L.). I. Depression of growth and yield. New Phytologist 113, 337-44.

$1989 b$. The effects of long-term open-air fumigation with $\mathrm{SO}_{2}$ on a field crop of broad bean (Vicia faba L.). II. Effects on growth components, leaf area development and elemental composition. New Phytologist 113, 34551.

MonTEITH, J. L., 1981. Does light limit crop production? pp. 23-38. In Physiological Processes Limiting Plant Productivity, ed. C. B. Johnson, 395 pp. Butterworths, London.

— and ELSTON, J., 1983. Performance and productivity of foliage in the field, pp. 499-518. In The Growth and Functioning of Leaves, eds J. E. Dale and F. L. Milthorpe, $540 \mathrm{pp}$. Cambridge University Press, Cambridge.

- and SCOTT, R. K., 1982. Weather and yield variation of crops, pp. 127-49. In Food, Nutrition and Climate, eds K. Blaxter and L. Fowden, $422 \mathrm{pp}$. Applied Science Publishers, London.

RICHARDS, F. J., 1969. The quantitative analysis of growth, pp. 1-76. In Plant Physiology a Treatise. VA. Analysis of Growth, ed. F. C. Steward, $435 \mathrm{pp}$. Academic Press, London.

Russell, G., Jarvis, P. G. and Monteith, J. L., 1989. Absorption of radiation by canopies and stand growth, pp. 21-39. In Plant Canopies, eds. G. Russell, B. Marshall, and P. G. Jarvis, 178 pp. Society for Experimental Biology Seminar Series, No. 31, Cambridge University Press, Cambridge.

Sibma, L., 1968. Growth of closed green crop surfaces in the Netherlands. Netherlands Journal of Agricultural Science 16, 211-16. 
